\title{
ROS Induced by KillerRed Targeting Mitochondria (mtKR) Enhances Apoptosis Caused by Radiation via Cyt c/Caspase- 3 Pathway
}

\author{
Xin Li, Fang Fang, Ying Gao, Geng Tang, Weiqiang Xu, Yihan Wang, Ruoxian Kong, \\ Ayixianguli Tuyihong, and Zhicheng Wang
}

NHC Key Laboratory of Radiobiology, School of Public Health, Jilin University, Changchun 130021, China

Correspondence should be addressed to Zhicheng Wang; zhicheng123a@126.com

Received 15 October 2018; Revised 2 January 2019; Accepted 22 January 2019; Published 7 March 2019

Academic Editor: Cinzia Domenicotti

Copyright (c) 2019 Xin Li et al. This is an open access article distributed under the Creative Commons Attribution License, which permits unrestricted use, distribution, and reproduction in any medium, provided the original work is properly cited.

\begin{abstract}
During radiotherapy, reactive oxygen species- (ROS-) induced apoptosis is one of the main mechanism of radiation. Based on KillerRed which can induce ROS burst in different cell substructures, here we hypothesized that KillerRed targeting mitochondria ( $\mathrm{mtKR}$ ) could induce ROS to enhance apoptosis by radiation. In this study, empty vector, mtKR, and mtmCherry plasmids were successfully constructed, and mitochondrial localization were detected in COS-7 and HeLa cells. After HeLa cells were transfected and irradiated by visible light and X-rays, ROS levels, mitochondrial membrane potential $\left(\Delta \psi_{\mathrm{m}}\right)$, ATPase activities, adenosine triphosphate (ATP) content, apoptosis, and the expressions of mRNA and protein were measured, respectively. Data demonstrated that the ROS levels significantly increased after light exposure, and adding extra radiation, voltage-dependent anion channel 1 (VDAC1) protein increased in the mitochondria, while $\mathrm{Na}^{+}-\mathrm{K}^{+}$and $\mathrm{Ca}^{2+}-\mathrm{Mg}^{2+} \mathrm{ATPase}$ activities, ATP content, and $\Delta \psi_{\mathrm{m}}$ significantly reduced. Additionally, the cell apoptotic rates dramatically increased, which referred to the increase of cytochrome $c$ (Cyt c), caspase-9, and caspase-3 mRNA expressions, and Cyt c protein was released from the mitochondria into the cytoplasm; caspase- 9 and -3 were activated. These results indicated that $\mathrm{mtKR}$ can increase the production of ROS, enhance mitochondrial dysfunction, and strengthen apoptosis by radiation via Cyt c/caspase-3 pathway.
\end{abstract}

\section{Introduction}

Mitochondria are essential organelles for cell survival, death, and signaling and are also one of the main production sites of reactive oxygen species (ROS) $[1,2]$. In addition, mitochondria also play a prominent role in the regulation of apoptosis [3-5]. When ROS is produced in the mitochondria, adenosine triphosphate (ATP) is also produced. ROS can be generated endogenously during cellular respiration or in response to infection and can be induced exogenously by chemical and physical agents, such as radiation, UV, and cigarette smoke. Lower levels of ROS play a role in normal cellular function [6], while increased levels of ROS induce oxidative stress which is the cause or consequence of the damage to mitochondria and mitochondrial DNA (mtDNA) [7].

In addition, mitochondria are also a damaging target of ROS. Under normal physiological conditions, ROS resulting from mitochondria is removed by a cellular antioxidant defense system. However, once ROS is overproduced, it will lead to the accumulation of excess radicals that damage the mitochondria and cells [8]. The literatures suggest that oxidative damage has also played a key role in diseases such as diabetes, Parkinson's disease, Alzheimer's disease, and even in the progress of cancers [9-11]. And ROS may mediate the programmed cell death (PCD) at a moderately high concentration among different cell types [12, 13]. In apoptosis, external stimuli such as radiation and cytotoxic agents can result in the formation of pores at mitochondrial membranes. Disruption of mitochondrial membrane potential $\left(\Delta \psi_{\mathrm{m}}\right)$ is a major sign of mitochondrial dysfunction. Loss of the $\Delta \psi_{\mathrm{m}}$ can result in a defective mitochondrial electron transport chain (ETC) and decrease metabolic oxygen consumption and ATP depletion [14]. Mitochondrial dysfunction results in the release of proapoptotic protein Cyt $\mathrm{c}$ and 
activates caspases to induce apoptosis. Once mitochondrial permeability transition pore (MPTP) is activated by oxidative stress, the membrane depolarization will develop, and the uncoupling of oxidative phosphorylation and ATP depletion will be induced [15]. Nowadays, the strategy targeting mitochondrial dysfunction in cancer therapy has been the research hotspots [16].

Radiotherapy is a conventional mean for cancer treatment for several decades. There is a growing interest in understanding how the altered mitochondrial functions may be the target to improve the effects of radiotherapy [17]. The modified bioenergetic and biosynthetic states of mitochondria play an eminent role for cancer cells in response to radiation [18]. Radiotherapy causes death of cancer cells through apoptosis and autophagy induced by excessive production of ROS [19-21]. Therefore, how to induce enough ROS to target mitochondria is a crucial research topic. KillerRed can directly express in cells, and under appropriate light excitation, it can efficiently induce ROS to cause cell death [22-25]. KillerRed can be used for the inactivation of light-induced protein, killing specific cell populations in vivo and studying intracellular local oxidative stress [26-28]. Additionally, because of light-inducing inactivation of KillerRed, in some studies, KillerRed was replaced by another red fluorescence protein mCherry (no phototoxicity) to study intracellular localization.

In this study, the N-terminal mitochondrial-targeting sequence (MTS) of PTEN-induced putative kinase 1 (Pink1) was used to mediate downstream mCherry and KillerRed to express in mitochondria [29]. Under fluorescence microscope, the colocalization of mCherry (red) and mitochondrial tracker COX IV (green) in both African green monkey kidney cell COS-7 and human cervical cancer cell HeLa was observed. Furthermore, we explored mtKR-induced mitochondrial dysfunction and apoptosis by light and X-rays, and proapoptotic mechanisms via Cyt c/caspase-3 pathway, to provide a new idea for cancer radiotherapy.

\section{Materials and Methods}

2.1. The mtmCherry and $m t K R$ Vectors. In this study, the DNAs of mCherry, KillerRed, and Pink1-MTS were amplified with PCR using Q5 High-Fidelity DNA Polymerase (NEB, Beverly, MA, USA), and plxsp-TetA-mCherry, plxsp-TetAKillerRed (kindly given by Dr. Shen from Cancer Institute of New Jersey, USA), and pcDNA-DEST47 PINK1 C-GF plasmids (Addgene, Cambridge, MA, USA) were used as templates. The following primers were used: mCherry: 5'-GGAATTCGCCACCATGGTGAGCAAGGG-3'(F), 5' CGGGATCCTTACTTGTACAGCTCGTCCATG-3'(R); KillerRed: 5'-GGAATTCATGGGTTCAGAGGGC-3'(F), 5' CGGGATCCCTAGATCTCGTCG-3'(R); Pink1-MTS: 5'-A AGGAAAAAAGCGGCCGCAATGGCGGTGCGACAG-3'(F), 5'-CGAATTCCGGCCGCCCCAAGCCGTAG-3'(R). The schematic diagram was shown in Figure 1(a), and the PCR products of mCherry, KillerRed, and Pink1-MTS were shown in Figure 1(b). All of the resulting plasmids were sequenced to verify that the clones had the correct sequence.
2.2. Cell Transfection and Observation with Fluorescence Microscope. COS-7 and HeLa cells were obtained from the ATCC (American Type Culture Collection). Both cell lines were maintained at $37^{\circ} \mathrm{C}$ under humidified conditions and $5 \% \mathrm{CO}_{2}$ and cultured in Dulbecco's modified Eagle's medium (DMEM, Gibco, Grand Island, NY, USA), supplemented with $10 \%$ fetal bovine serum (MRC, Jiangsu, China). COS-7 and HeLa cells were seeded into a 6 -well plate with coverslips at $2 \times 10^{5} /$ well and routinely incubated for $8-12 \mathrm{~h}$ without light. The mtmCherry plasmids were transfected into the cells with Hieff Trans ${ }^{\mathrm{TM}}$ Liposomal Transfection Reagent (Shanghai YESEN Biotechnology Co., Ltd.). At $30 \mathrm{~h}$ posttransfection, the coverslips were taken out, and the cells were fixed in PBS with $4 \%$ paraformaldehyde for $10 \mathrm{~min}$ at room temperature (RT), permeabilized and blocked with sealing fluid (0.3\% Triton X-100 and 2\% BSA in PBS) for $1 \mathrm{~h}$ at RT. The cells were incubated with COX IV antibody diluted in sealing fluid overnight at $4^{\circ} \mathrm{C}$, followed by incubation with secondary antibodies (green fluorescence) diluted in sealing fluid for $1 \mathrm{~h}$ at $37^{\circ} \mathrm{C}$. The coverslips were mounted onto microscope slides; mCherry and COX IV expressions were observed under fluorescence microscope. The images were processed for analyzation.

2.3. ROS Detection. HeLa cells were transfected with empty vector and $\mathrm{mtKR}$ plasmids for $30 \mathrm{~h}$ and exposed to visible light for 10,30, and $60 \mathrm{~min}$, respectively, then at 10, 30, and $60 \mathrm{~min}$ after exposure, $2^{\prime}, 7^{\prime}$-dichlorofluorescein diacetate (DCFH-DA, Sigma-Aldrich, St. Louis, MO, USA) was added into the cells. Finally, the mean fluorescence intensity (MFI) was detected by Cytation ${ }^{\mathrm{TM}} 3$ Cell Imaging Multi-Mode Reader System (BioTek, Winooski, Vermont, USA). There were 6 replicate wells per group, and the experiment was performed in triplicate.

2.4. Detections of $\mathrm{Na}^{+}-\mathrm{K}^{+}$and $\mathrm{Ca}^{2+}-\mathrm{Mg}^{2+}$ ATPase Activities and ATP Content. At $12 \mathrm{~h}$ postlight exposure, HeLa cells were irradiated by $4 \mathrm{~Gy}$ X-rays with X-RAD 320iX machine (Precision X-ray, Inc., USA), at $24 \mathrm{~h}$ postirradiation, the cells were homogenized using homogenate medium $(\mathrm{pH} 7.4,0.01 \mathrm{M}$ Tris- $\mathrm{HCl}, 0.001 \mathrm{M}$ EDTA-2Na, 0.01 M saccharose, and $0.8 \%$ $\mathrm{NaCl}$ ) (Nanjing Jiancheng Bioengineering Institute, China), and protein concentrations were determined. $\mathrm{Na}^{+}-\mathrm{K}^{+}$and $\mathrm{Ca}^{2+}-\mathrm{Mg}^{2+}$ ATPases and ATP were measured using biochemical assay kits (Nanjing Jiancheng Bioengineering Institute, China) and a spectrophotometer (Beckman, USA) with $636 \mathrm{~nm}$ excitation wavelengths. There were 4 replicate wells per group, and the experiment was performed in triplicate.

2.5. Flow Cytometry (FCM). Rhodamine123 (Rh123, Sigma-Aldrich, St. Louis, MO, USA) was used to detect $\Delta \psi_{\mathrm{m}}$, and Annexin V-FITC/PI kit (Becton, Dickinson and Company, Franklin Lakes, NJ, USA) was used to measure apoptotic rate. The collected cells were resuspended at $12 \mathrm{~h}$ postirradiation, then, Rh123 was added into the cells to yield final concentrations of $5 \mu \mathrm{M}$ for detecting $\Delta \psi_{\mathrm{m}}$ and stained with $10 \mu \mathrm{l}$ Annexin V-FITC and PI for $15 \mathrm{~min}$ in the dark for detecting apoptotic rate. Then the $\Delta \psi_{\mathrm{m}}$ and apoptotic rate were detected by FCM (Becton, Dickinson and Company, 

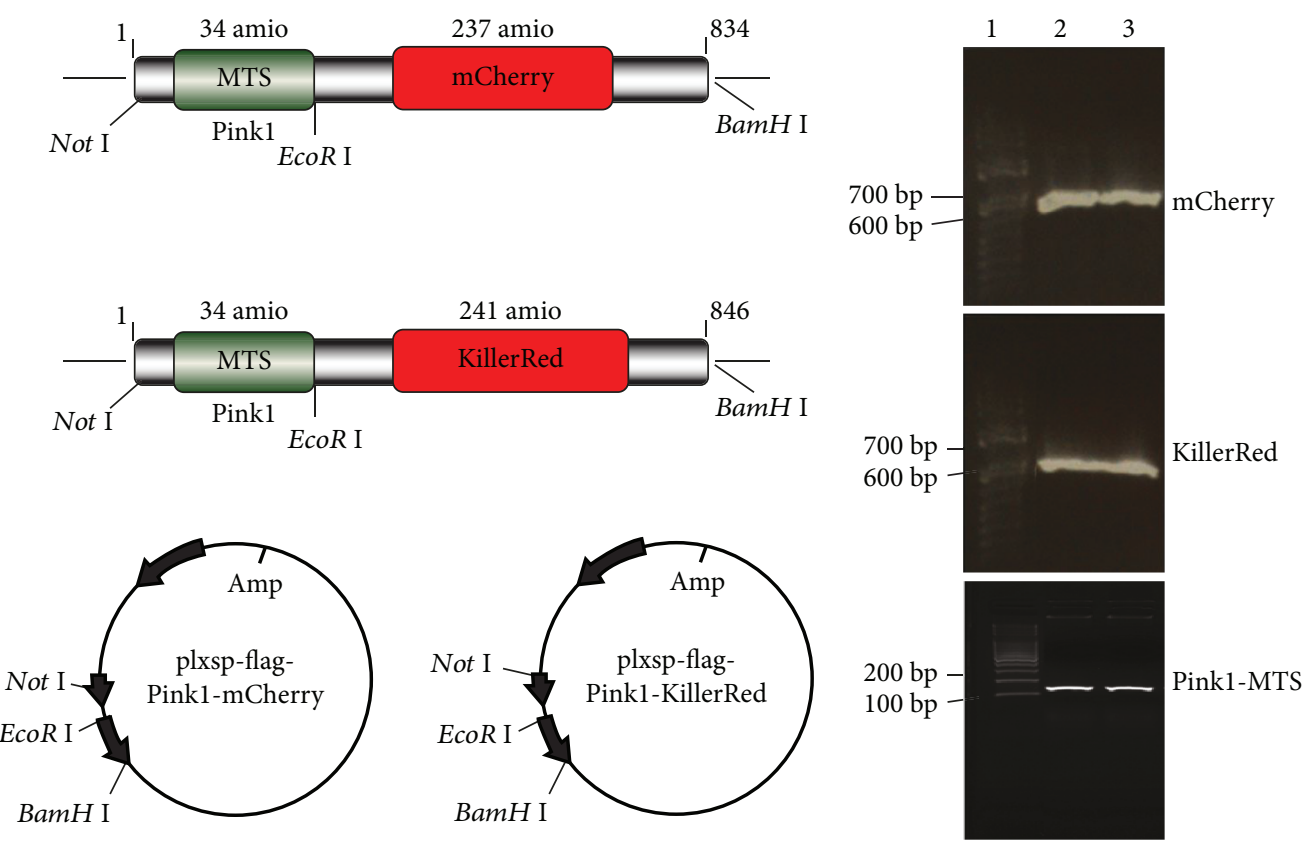

(b)

FIGURE 1: Development of vectors for mtmCherry and mtKR. (a) Schematic diagram of mtmCherry and mtKR vectors: Pink1-MTS was cloned into empty vector (plxsp-flag) (Not I and EcoR I sites); mCherry and KillerRed were cloned into plxsp-flag-Pink1-MTS (EcoR I and BamH I sites). (b) PCR products of mCherry, KillerRed, and Pink1-MTS. Lane 1 was 100 bp DNA Marker; lane 2 and 3 were PCR amplification products.

Franklin Lakes, NJ, USA). For each sample, at least $1 \times 10^{4}$ cells were collected. There were 4 replicate wells per group. The experiment was performed in triplicate.

2.6. Quantitative Real-Time PCR ( $q R T-P C R)$. Total RNA was extracted with TRIzol reagents (Invitrogen, Carlsbad, CA, USA), and the complementary DNA (cDNA) was synthesized using a high-capacity reverse transcription kit (Takara Bio Inc., Japan). The reverse transcription of $1 \mu \mathrm{g}$ RNA was performed according to the protocol, and the reaction was incubated at $42^{\circ} \mathrm{C}$ for $60 \mathrm{~min}$, then at $70^{\circ} \mathrm{C}$ for $2 \mathrm{~min}$. GAPDH: $5^{\prime}$-ACCACAGTCCATGCCATCAC-3'(F), $5^{\prime}$-TC CACCACCCTGTTGCTGTA-3'(R); Cyt c: $5^{\prime}$-GGGCGA GAGCTATGTAATGCAAG-3'(F), $5^{\prime}$-TACAGCCAAAGC AGCAGCTCA-3'(R); caspase-9: $5^{\prime}$-GGACATCCAGCGGG CAGG-3' (F), 5' -TCTAAGCAGGAGATGAACAAAGG-3' (R); caspase-3: $5^{\prime}$-TTCAGGCCTGCCGTGGTACA-3'(F), $5^{\prime}$-CCAAGAATAATAACCAGGTGCT-3' ${ }^{\prime}(\mathrm{R})$. The qRT-PCR reaction was performed and analyzed (Bio-Rad, Hercules, CA, USA) according to SYBR ${ }^{\circledR}$ Premix Ex Taq ${ }^{\text {TM }}$ II kit (Takara Bio Inc., Japan) protocol.

2.7. Mitochondrial Protein Extraction. The cells were washed with $0.01 \mathrm{M}$ PBS and collected at $\times 200 \mathrm{~g}$ for $5 \mathrm{~min}$, added with $3 \mathrm{ml}$ mitochondrial separation reagents (Beyotime ${ }^{\circledR}$ Biotechnology, Hangzhou, China) consisting of PMSF and put on ice for $10 \mathrm{~min}$. The cell homogenate was transferred into glass homogenizer, performed for $30 \mathrm{~min}$, and centrifuged at $\times 600 \mathrm{~g}$ at $4^{\circ} \mathrm{C}$ for $10 \mathrm{~min}$. The suspension was transferred to another tube and centrifuged at $\times 11000 \mathrm{~g}$ at $4^{\circ} \mathrm{C}$ for $10 \mathrm{~min}$. When the suspension was removed after centrifugation, the mitochondria were obtained. Then the mitochondrial proteins were extracted and quantitatively determined.

2.8. Western Blot. After the total proteins were extracted and quantitatively determined, $40 \mu \mathrm{g}$ proteins were separated by SDS-PAGE (10\% resolving gel, 5\% stacking gel) and transferred to NC membrane (200 mA, 1.5 h; Merck Millipore, Billerica, MA, USA). After blocking with 5\% nonfat dry milk, the membranes were incubated with diluting solution $(1: 200)$ of the primary antibodies including anti-VDAC1, anti-HSP60 and anti-Cyt c (Bioworld Technology Inc., USA), anti-caspase-9 (cleaved) and anti-caspase-3 (cleaved) (Cell Signaling Technology, Danvers, MA, USA), and anti-GAPDH (Santa Cruz, CA, USA), respectively, overnight at $4^{\circ} \mathrm{C}$. After washing with TBST, the membranes were incubated with IgG-HRP-conjugated secondary antibody (ImmunoWay, Plano, TX, USA) at 1:1000 dilution for $1.5 \mathrm{~h}$ at RT. Finally, the membranes were identified using an enhanced chemiluminescence detection system (ECL detection kit, Santa Cruz, CA, USA). The films were scanned for the following gray scale ratio analysis.

2.9. Statistical Analysis. All the data were analyzed using SPSS, version 24.0 (SPSS Inc., Chicago, IL, USA). The results were presented as mean $\pm \mathrm{SD}$ and subjected to one-way ANOVA followed by Student's $t$-test; $P<0.05$ was considered as significant. 

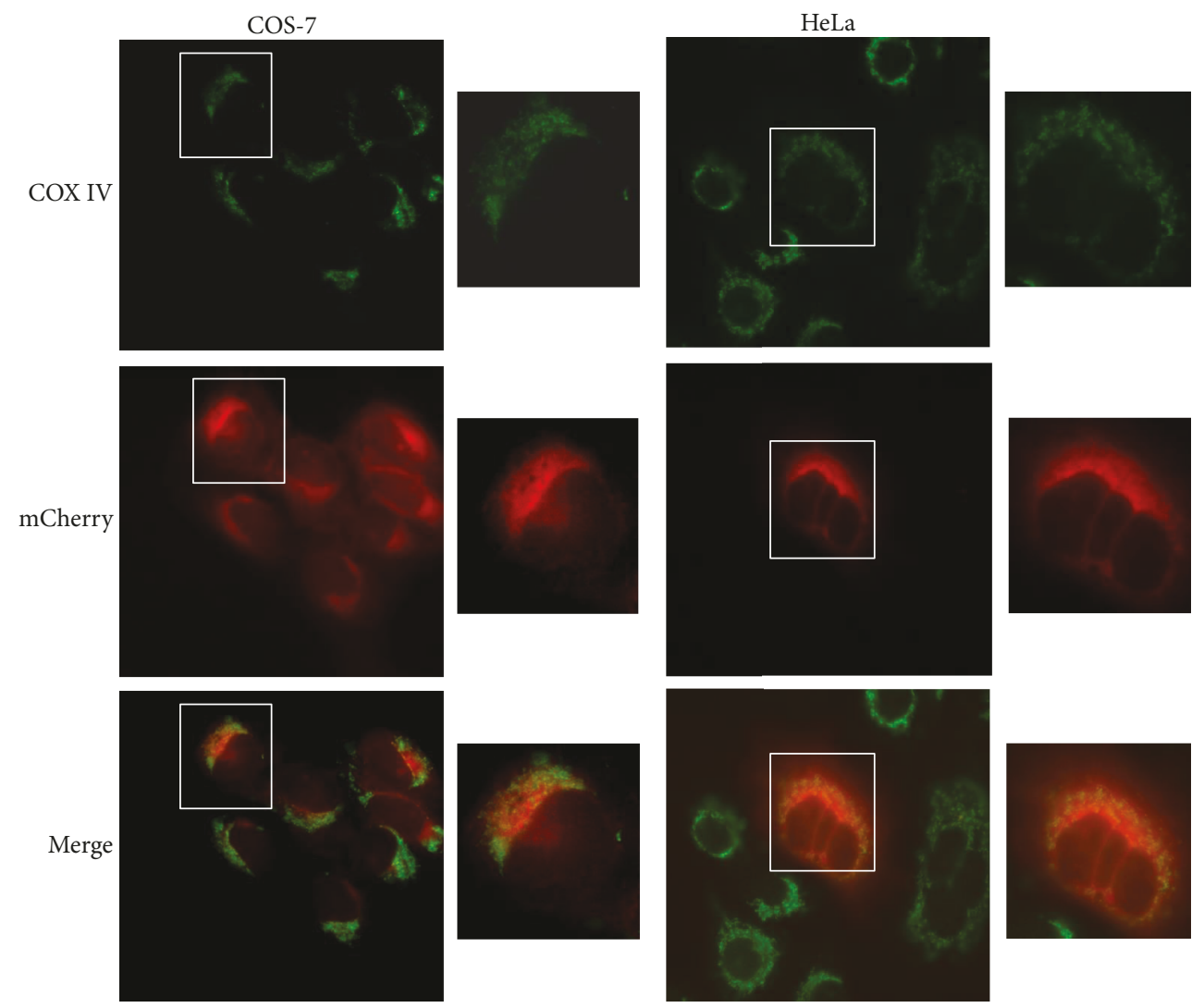

FIGURE 2: The mtmCherry colocalized the mitochondria with COX IV, $\times 200$. COS -7 and HeLa cells were transfected with mtmCherry plasmids. At $30 \mathrm{~h}$ posttransfection, the cells were stained with COX IV, and COX IV (green) and mCherry (red) expressions were observed.

\section{Results}

3.1. The mtmCherry Protein to Localize Mitochondria. As shown in Figure 2, the fluorescence images clearly indicated that COX IV expressed in the mitochondria, and mCherry also specifically localized to the same sites. Hence, it demonstrated that Pink1-MTS sequence might mediate mCherry to localize mitochondria.

3.2. ROS Induced by mtKR Exposed to Visible Light. As shown in Figure 3(a), before light exposure, there were a large amount of red cells and very few green cells; after light exposure, red cells decreased and green cells increased, indicating ROS production. As shown in Figure 3(b), at 60 min post-10 or -30 min light exposure, MFIs reached for maximum value, but at 30 or $60 \mathrm{~min}$ post $60 \mathrm{~min}$ light exposure, MFIs reduced. Taken together, these results indicated that light exposure caused the inactivation of $\mathrm{mtKR}$ protein and the increase of ROS.

3.3. Mitochondrial Dysfunction Caused by $m t K R$ and Irradiation. The $\mathrm{Na}^{+}-\mathrm{K}^{+}$and $\mathrm{Ca}^{2+}-\mathrm{Mg}^{2+}$ ATPase activities and ATP content significantly decreased after light exposure and irradiation (Figure 4(a)). Additionally, even though $\Delta \psi_{\mathrm{m}}$ significantly reduced, it had similar change regularity as ATPase activities (Figure 4(b)). As shown in Figures 4(c) and 4(d), VDAC1 expressions in total and mitochondrial proteins were all increased, but after $4 \mathrm{~Gy}$ irradiation, VDAC1 decreased in total protein. Taken together, these results showed that $m$ tKR-induced ROS and X-rays caused mitochondrial dysfunction, and MPTP was kept in opening status.

3.4. Changes of Apoptotic Rate Caused by $m t K R$ and Irradiation via Cyt c/Caspase-3 Pathway. At $12 \mathrm{~h}$ postirradiation, early apoptotic rates caused by $\mathrm{mtKR}$ exposure to light were significantly increased, and $4 \mathrm{~Gy}$ X-rays also induced the increase of apoptotic rate (Figure 5(a)). As shown in Figure $5(\mathrm{~b})$, at $24 \mathrm{~h}$ postirradiation, the mRNA expressions of Cyt c, caspase-9, and caspase-3 dramatically increased. And caspase- 9 and -3 proteins were cleaved into active fragments in total proteins; Cyt c protein expression reduced in mitochondrial protein; however, it increased in total protein (Figures 5(c) and 5(d)).

\section{Discussion}

Radiotherapy is the major means of cancer treatments, and its major feature is the induction of toxic oxidative damage in targeted cancer cells. Under normal physiological condition, cells maintain a basal redox balance between prooxidative and antioxidative reactions [30]. During radiation, ROS generated from water by radiation energy deposition can oxidize DNAs, proteins, and lipids and target mitochondria to 

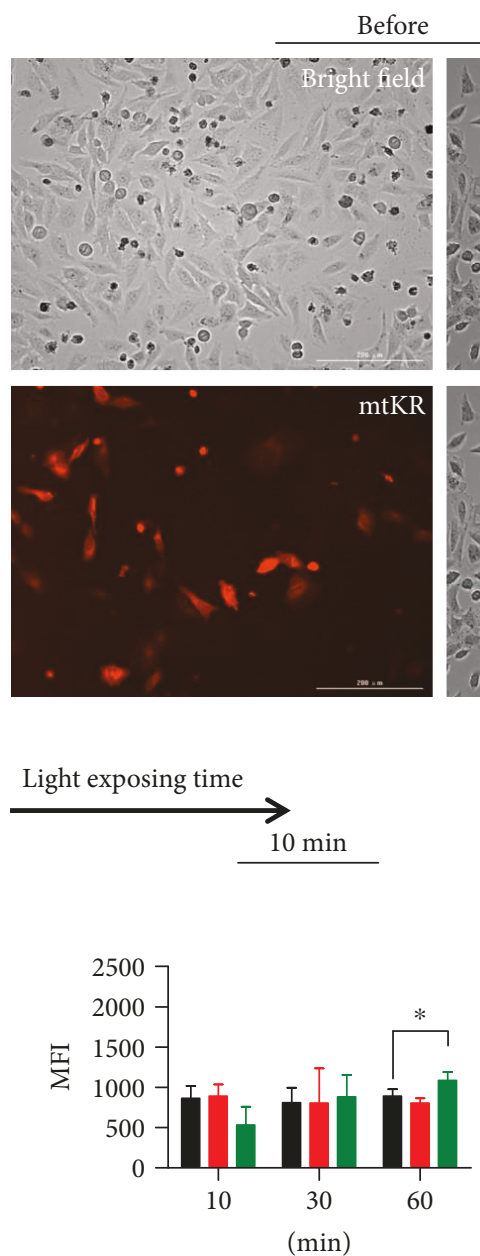

- Con

- Empty vector

- mtKR

Time after light exposure
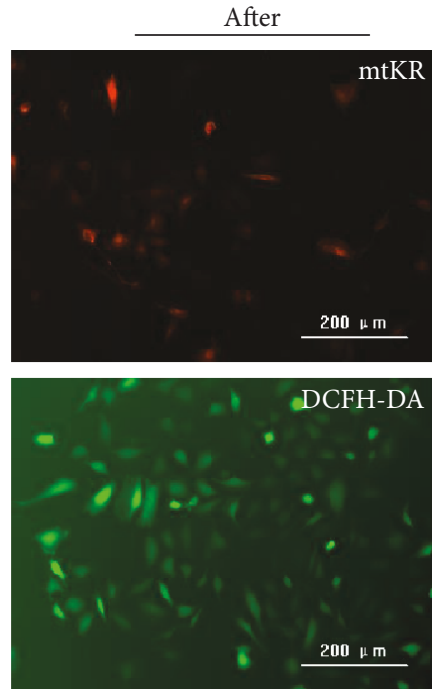

(a)

$30 \mathrm{~min}$
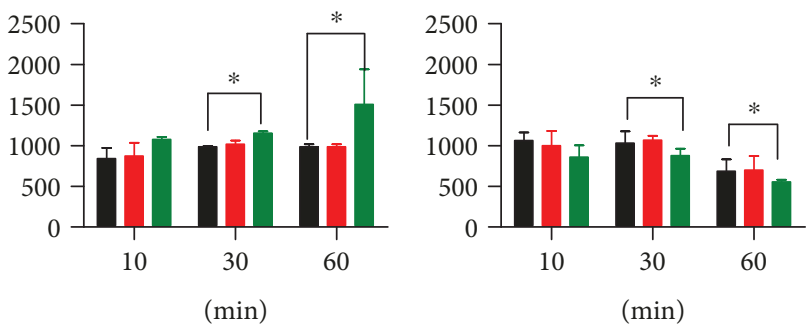

(b)

FIgURE 3: ROS changes measured by DCFH-DA staining. (a) The images of mtKR (red) before or after light exposure for 30 min in HeLa cells and cells stained by DCFH-DA (green), scale bars: $200 \mu \mathrm{m}$. (b) The changes of MFIs at different time postlight exposure for 10, 30, and 60 min, respectively. The bars represent the mean $\pm \mathrm{SD}$ of triplicate measurements. ${ }^{*} P<0.05$ versus control.

cause mitochondrial dysfunction and final cell death. Moreover, the ROS has extremely short lifespan and a limited diffusion distance leading to low killing efficiency to tumor cells and unsatisfactory therapeutic effects [31-33]. In this study, based on KillerRed-induced ROS, we utilized Pink1-MTS to mediate mitochondrial localization, and our results also indicated our hypothesis. In addition, our data showed that mtKR might promote mitochondrial ROS burst. The nature of the cytotoxicity of KillerRed, a generator of ROS, therefore offers a significant opportunity to genetically investigate the mechanisms regulating cellular responses.

Mitochondrion is an ancient organelle generating approximately $90 \%$ of cellular ATP via oxidative phosphorylation [34]. Unlike normal cells, there is an abnormal redox status in cancer cells, which is unable to regulate redox homeostasis [35]. It is postulated that mitochondrial dysfunction in cancer cells would affect the relative cellular ATPase activities, ATP production, and subsequent apoptosis and migration processes. In the present study, the relative ATPase activity and ATP in HeLa cells transfected by mtKR plasmids were significantly decreased. Moreover, various evidences suggest that the mitochondrial dysfunction plays a key role in oxidative stress [36, 37], and ROS generation impairs mitochondrial electron transport chain [38]. The decline in $\Delta \psi_{\mathrm{m}}$ is an earlier event in the process of cell death, and we also showed that mtKR-induced ROS can result in the loss of $\Delta \psi_{\mathrm{m}}$. VDAC is the most abundant protein in the outer mitochondrial membrane, and the fact that VDAC plays a role in MTPT is undeniable, so it has long been considered to be a candidate for the outer membrane component of 

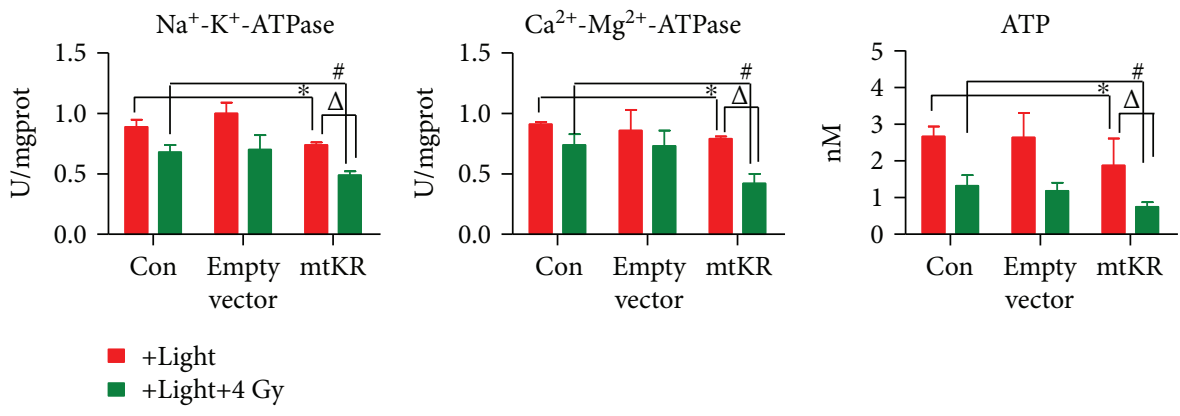

(a)
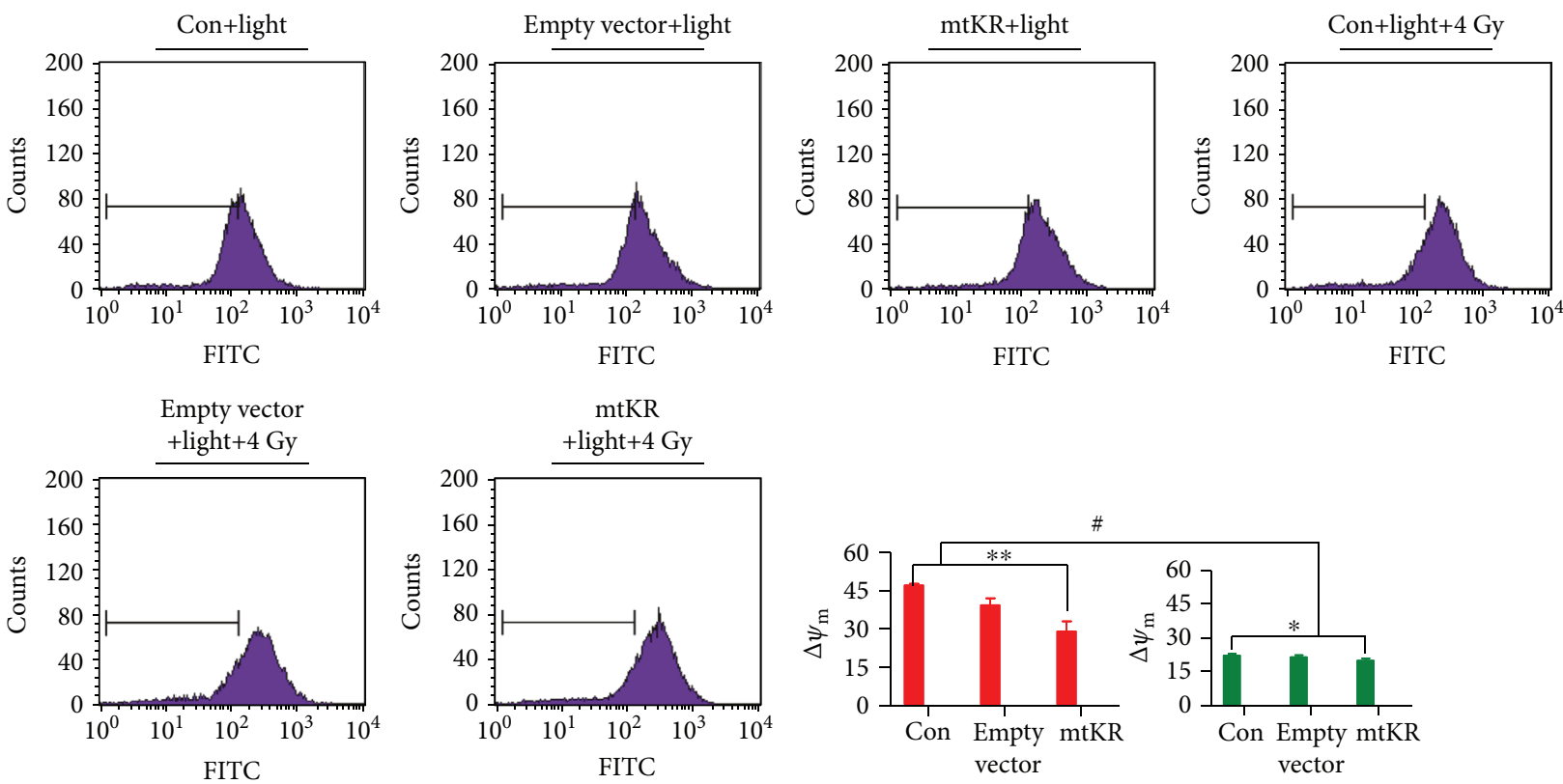

+ + Light

- +Light+4 Gy

(b)
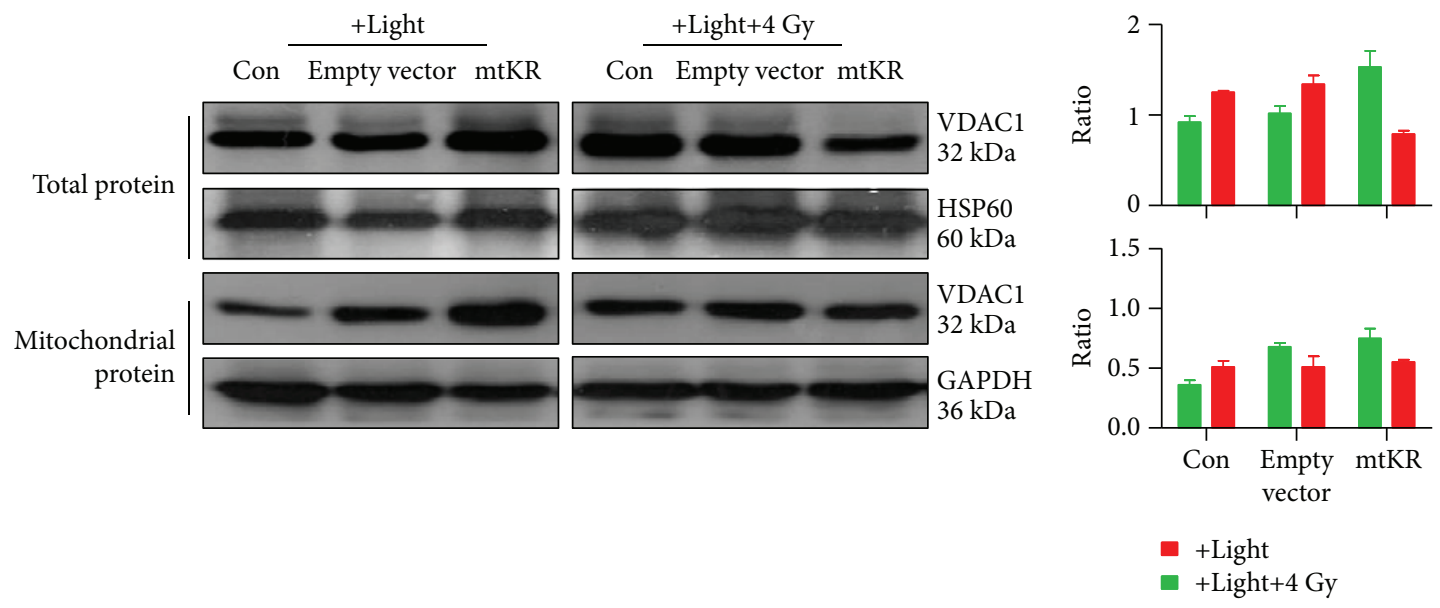

(c)

Figure 4: Mitochondrial dysfunctions caused by mtKR-induced ROS and X-rays. (a) The changes of $\mathrm{Na}^{+}-\mathrm{K}^{+}$and $\mathrm{Ca}{ }^{2+}-\mathrm{Mg}^{2+} \mathrm{ATPase}^{-}$ activities and ATP content by biochemical assay after light exposure and irradiation. (b) The FCM pictures of $\Delta \psi_{\mathrm{m}}$. HeLa cells were stained by Rh123, followed by FCM analysis of the $\Delta \psi_{\mathrm{m}}$. (c) Western blot analysis was performed to determine the protein levels of VDAC1 in total and mitochondrial protein. GAPDH and HSP60 proteins were used for loading control. (d) From top to bottom, the gray ratios of VDAC1/GAPDH and VDAC1/HSP60. The bars represent the mean \pm SD of triplicate measurements. ${ }^{*} P<0.05$ versus control; \# $P<0.05$ versus 4 Gy irradiation, and ${ }^{\triangle} P<0.05$ versus light exposure. 

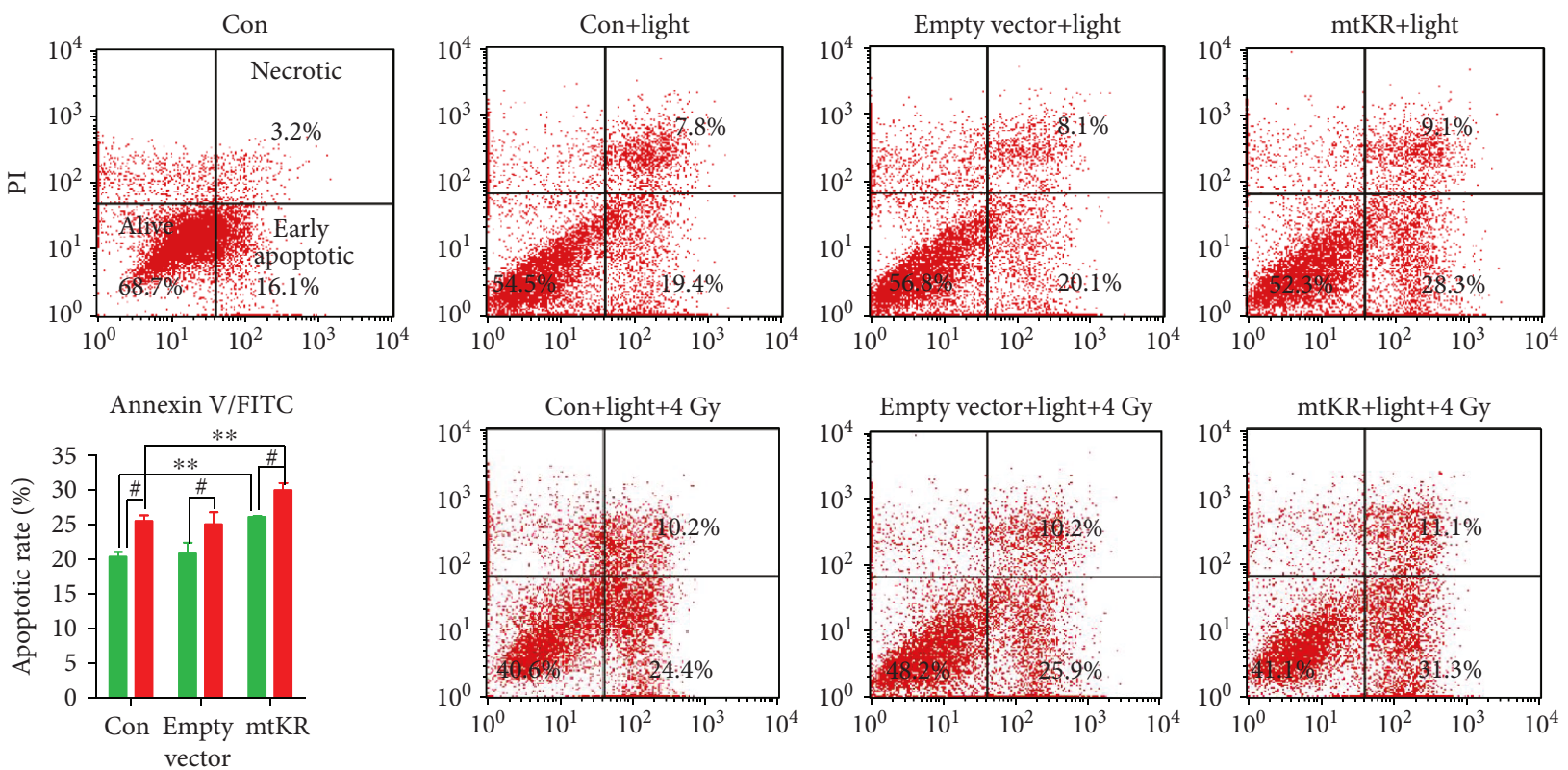

- +Light+4 Gy

- +Light

(a)
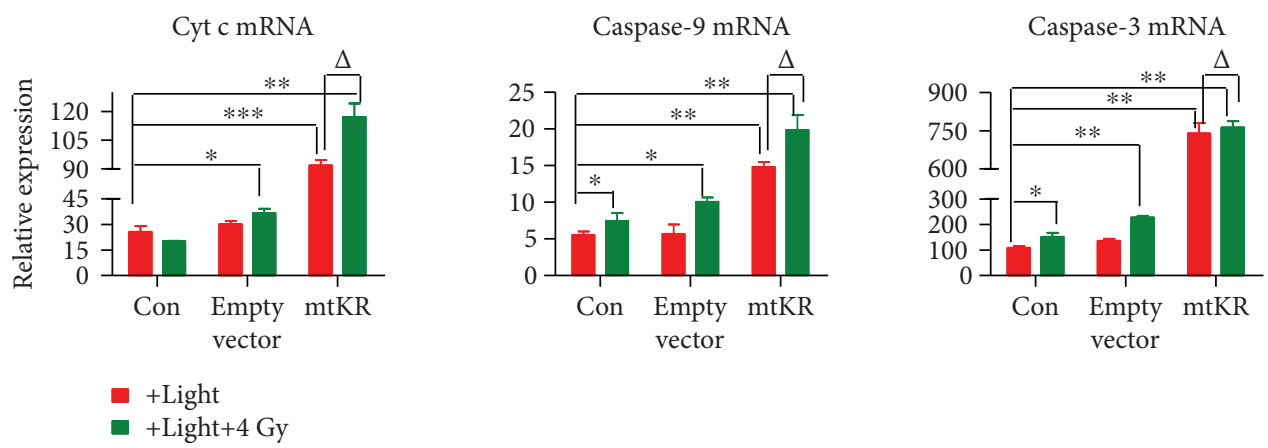

(b)

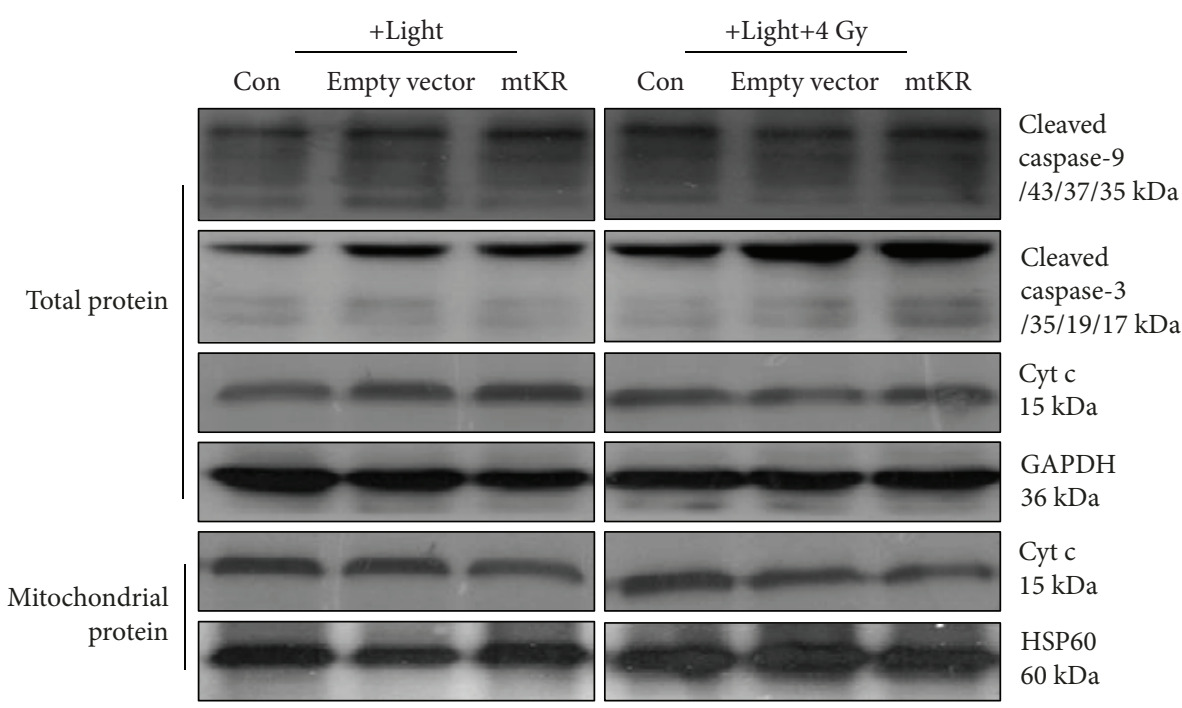

(c)

Figure 5: Continued. 


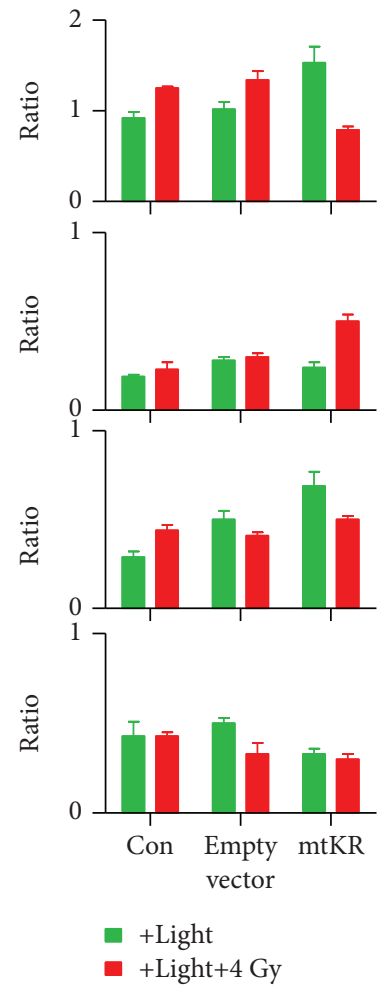

(d)

FIgURE 5: Apoptosis induced by mtKR and irradiation via Cyt c/caspase-3 pathway. (a) The FCM pictures of apoptosis and FCM analysis in HeLa cells stained by Annexin V/FITC and PI; the apoptotic population was defined as early apoptosis (lower right, green of FITC staining). (b) Cyt c, caspase-9, and caspase-3 mRNAs were detected by qRT-PCR. (c) Western blot was performed to determine the protein levels of Cyt c, caspase-9, and caspase-3 in total and mitochondrial proteins. GAPDH and HSP60 proteins were used for loading control. (d) From top to bottom, the gray ratios of cleaved caspase-9/GAPDH, cleaved caspase-3/GAPDH, Cyt c/GAPDH, and Cyt c/HSP60. The bars represent the mean \pm SD of triplicate measurements. ${ }^{*} P<0.05,{ }^{* *} P<0.01$, and ${ }^{* * *} P<0.001$ versus control; ${ }^{*} P<0.05$ versus 4 Gy irradiation, and ${ }^{\triangle} P<0.05$ versus light exposure.

the MPTP [39]. Recently, it has been shown that the opening of VDAC is a regulated process, and VDAC may exhibit some degree of specificity in the mitochondrial import/ export of molecules (e.g., ATP, $\mathrm{Ca}^{2+}$, and other ions) [40]. In some studies, VDAC1-deficient mitochondria isolated from a mutant yeast strain failed to exhibit the Bax/Bakinduced $\Delta \psi_{\mathrm{m}}$ loss and Cyt $\mathrm{c}$ release that was observed with VDAC1-expressing control mitochondria [41]. Our results showed that VDAC1 protein expression significantly increased in total and mitochondrial proteins, indicating an opening status of the mitochondrial membrane. In addition, it is well known that radiation-induced increase in ROS causes DNA damage, cell cycle arrest, and activation of some transcription and apoptotic factors [42, 43]. Thus, the hypothesis that $\mathrm{mtKR}$ aggravates the mitochondrial dysfunction induced by radiation is understandable. Interestingly, our results also verify this hypothesis.

There are two major pathways in apoptosis [44]. One involves death receptors and is marked by Fas-mediated caspase- 8 activation, and the other is the stress- or mitochondrial-mediated caspase- 9 and -3 activation. Mitochondria are the major source of ROS production in cells, in turn, the most adversely affected organelles [45]. To better understand the mechanism that ROS leads to apoptosis, we demonstrated in this study that an acute burst of ROS in the mitochondria specifically resulted in the apoptosis, the subsequent Cyt $\mathrm{c}$ release and activation of caspase- 9 and -3 . Our results showed a promoting role on the apoptosis resulting from $\mathrm{mtKR}$, which might be enhanced by radiation, and had impressive significance for tumor radiotherapy. The releases of Cyt $\mathrm{c}$ as well as other proteins from the mitochondria and cytosol appear to play a central role in the induction of the apoptotic cascade that ultimately leads to the programmed cell death [46]. To further explore the mechanisms, we analyzed the transcriptional levels and protein expressions of Cyt c, caspase-9, and caspase- 3 at $24 \mathrm{~h}$ postirradiation, and their mRNA levels all increased. Interestingly, Cyt c protein expression increased in total protein however reduced in mitochondrial protein. Moreover, radiation could enhance these effects of $m t K R$, which indicated that Cyt $\mathrm{c}$ was released from the mitochondria. Under the downstream of mitochondrial apoptotic pathway, caspase- 9 and -3 were activated (Figures 5(c) and 5(d)), which made us believe mtKR induced-ROS might act synergistically with radiation to induce the apoptosis via Cyt c/caspase- 3 pathway. 


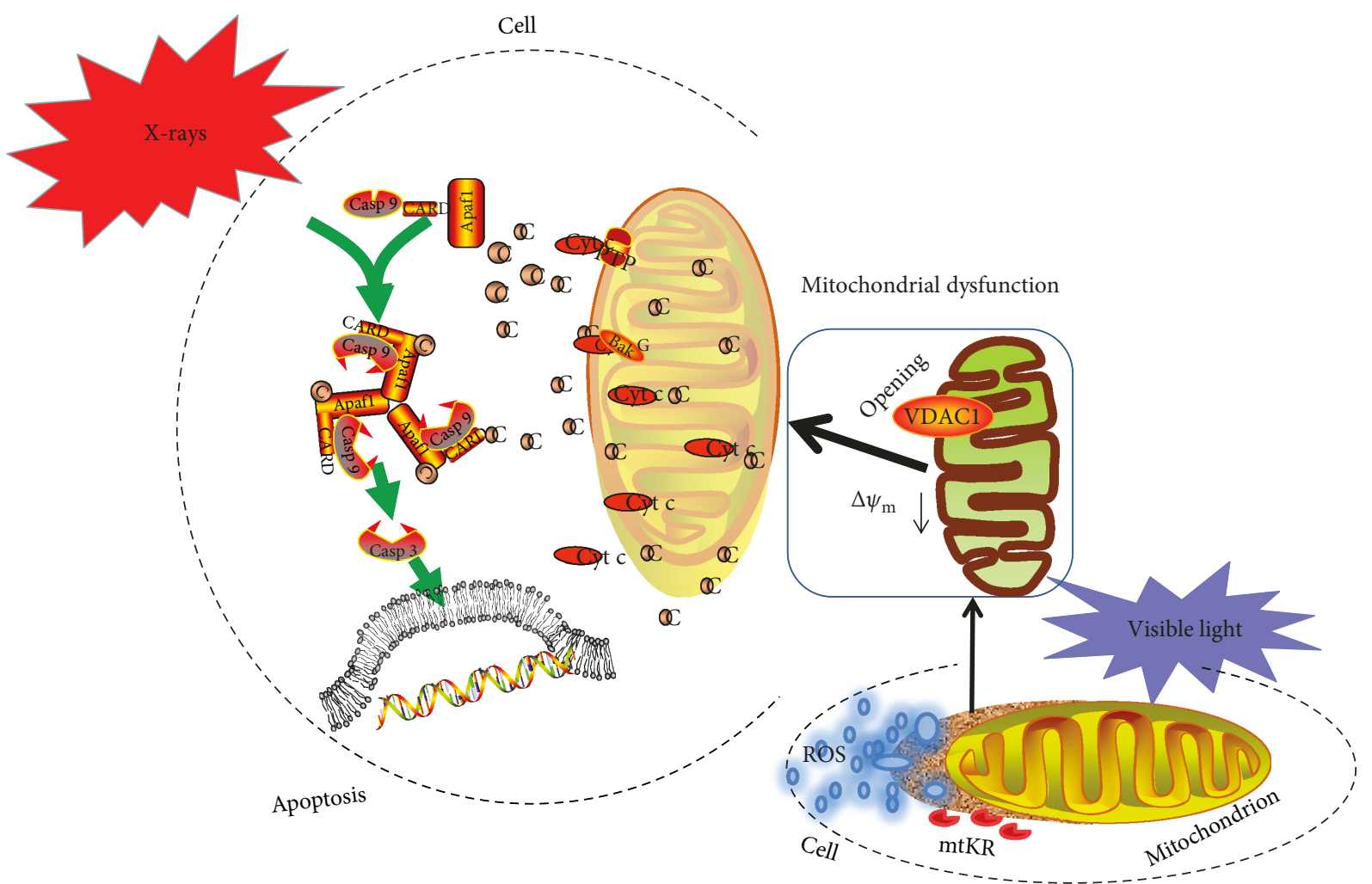

FIGURE 6: The proposed scheme of apoptosis induced by mtKR and radiation via Cyt c/caspase-3 pathway.

In conclusion, as illustrated in Figure 6, this present study demonstrates that the mitochondrial targeting characteristics of Pink-MTS and ROS increased by mtKR exposure to visible light in HeLa cells and then to impaired mitochondrial function. When ATPase activities and ATP content as well as $\Delta \psi_{\mathrm{m}}$ reduced, and VDAC1 expression increased, the cell apoptosis also increased dependently on the Cyt c/caspase-3 pathway. Notably, mitochondrial dysfunction and final apoptosis enhanced by radiation has provided a new strategy for ROS sensitization in future clinical cancer therapy.

\section{Data Availability}

In these studies, all data were obtained by PCR technique, flow cytometry (FCM), biochemical assay, observation by fluorescence microscope, quantitative real-time PCR, and Western blot, and some pictures were plotted using different tools, such as BVTech plasmid software, Adobe Photoshop CS2 software, SPSS 24.0 version, GraphPad prism 6.0 software, and PPT of Microsoft office, ScienceSlides, etc. The data (the schematic diagram of vector construction, the cell picture under fluorescence microscope, some pictures drawn with experiment results by GraphPad prism 6.0 software, FCM pictures, Western blot pictures, and the proposed scheme of conclusions) used to support the findings of this study are included within the article.

\section{Conflicts of Interest}

The authors declare that there is no conflict of interests regarding the publication of this paper.

\section{Authors' Contributions}

Xin Li and Fang Fang contributed equally in this work.

\section{Acknowledgments}

This work was supported by grants from the National Nature Science Foundation of China (81803218), the Jilin Health Technology Innovation (2016J069, 2017Q023), the Science and Technology Research Projects of the Education Department of Jilin Province (JJKH20170828K and JJKH2018 0189KJ), and the Science and Technology Development Plan of Jilin (20180101305JC). The authors are also thankful for the plasmids kindly given by Dr. Zhiyuan Shen from the Cancer Institute of New Jersey and for the modification of the manuscript by Dr. Shouliang Gong from Jilin University.

\section{References}

[1] H. M. McBride, M. Neuspiel, and S. Wasiak, "Mitochondria: more than just a powerhouse," Current Biology, vol. 16, no. 14, pp. R551-R560, 2006.

[2] J. Allen, R. Romay-Tallon, K. J. Brymer, H. J. Caruncho, and L. E. Kalynchuk, "Mitochondria and mood: mitochondrial 
dysfunction as a key player in the manifestation of depression," Frontiers in Neuroscience, vol. 12, p. 386, 2018.

[3] P. X. Petit, S. A. Susin, N. Zamzami, B. Mignotte, and G. Kroemer, "Mitochondria and programmed cell death: back to the future," FEBS Letters, vol. 396, no. 1, pp. 7-13, 1996.

[4] R. A. Gottieb, "Mitochondria and apoptosis," Biological Signals and Receptors, vol. 10, no. 3-4, pp. 147-161, 2001.

[5] P. A. Henkart and S. Grinstein, "Apoptosis: mitochondria resurrected," The Journal of Experimental Medicine, vol. 183, no. 4, pp. 1293-1295, 1996.

[6] H. Vakifahmetoglu-Norberg, A. T. Ouchida, and E. Norberg, "The role of mitochondria in metabolism and cell death," Biochemical and Biophysical Research Communications, vol. 482, no. 3, pp. 426-431, 2017.

[7] X. Xie, Y. Chen, L. Ma et al., "Major depressive disorder mediates accelerated aging in rats subjected to chronic mild stress," Behavioural Brain Research, vol. 329, pp. 96-103, 2017.

[8] D. B. Zorov, C. R. Filburn, L. O. Klotz, J. L. Zweier, and S. J. Sollott, "Reactive oxygen species (ROS)-induced ROS release: a new phenomenon accompanying induction of the mitochondrial permeability transition in cardiac myocytes," The Journal of Experimental Medicine, vol. 192, no. 7, pp. 1001-1014, 2000.

[9] K. Rashid, J. Das, and P. C. Sil, “Taurine ameliorate alloxan induced oxidative stress and intrinsic apoptotic pathway in the hepatic tissue of diabetic rats," Food and Chemical Toxicology, vol. 51, pp. 317-329, 2013.

[10] K. Sinha, J. Das, P. B. Pal, and P. C. Sil, "Oxidative stress: the mitochondria-dependent and mitochondria-independent pathways of apoptosis," Archives of Toxicology, vol. 87, no. 7, pp. 1157-1180, 2013.

[11] G. Farrugia and R. Balzan, "Oxidative stress and programmed cell death in yeast," Frontiers in Oncology, vol. 2, p. 64, 2012.

[12] S. G. Rhee, "Cell signaling. $\mathrm{H}_{2} \mathrm{O}_{2}$, a necessary evil for cell signaling," Science, vol. 312, no. 5782, pp. 1882-1883, 2006.

[13] M. Valko, D. Leibfritz, J. Moncol, M. T. D. Cronin, M. Mazur, and J. Telser, "Free radicals and antioxidants in normal physiological functions and human disease," The International Journal of Biochemistry \& Cell Biology, vol. 39, no. 1, pp. 4484, 2007.

[14] J. L. Vayssiere, P. X. Petit, Y. Risler, and B. Mignotte, “Commitment to apoptosis is associated with changes in mitochondrial biogenesis and activity in cell lines conditionally immortalized with simian virus 40," Proceedings of the National Academy of Sciences of the United States of America, vol. 91, no. 24, pp. 11752-11756, 1994.

[15] P. X. Petit, H. Lecoeur, E. Zorn, C. Dauguet, B. Mignotte, and M. L. Gougeon, "Alterations in mitochondrial structure and function are early events of dexamethasone-induced thymocyte apoptosis," The Journal of Cell Biology, vol. 130, no. 1, pp. 157-167, 1995.

[16] J. Rohlena, L. F. Dong, S. J. Ralph, and J. Neuzil, "Anticancer drugs targeting the mitochondrial electron transport chain," Antioxidants \& Redox Signaling, vol. 15, no. 12, pp. 29512974, 2011.

[17] M. W. van Gisbergen, A. M. Voets, M. H. W. Starmans et al., "How do changes in the mtDNA and mitochondrial dysfunction influence cancer and cancer therapy? Challenges, opportunities and models," Mutation Research/Reviews in Mutation Research, vol. 764, pp. 16-30, 2015.

[18] V. Bol, A. Bol, C. Bouzin et al., "Reprogramming of tumor metabolism by targeting mitochondria improves tumor response to irradiation," Acta Oncologica, vol. 54, no. 2, pp. 266-274, 2015.

[19] M. Dewaele, H. Maes, and P. Agostinis, "ROS-mediated mechanisms of autophagy stimulation and their relevance in cancer therapy," Autophagy, vol. 6, no. 7, pp. 838-854, 2010.

[20] G. L. Bellot, D. Liu, and S. Pervaiz, "ROS, autophagy, mitochondria and cancer: Ras, the hidden master," Mitochondrion, vol. 13, no. 3, pp. 155-162, 2013.

[21] F. Nicolau-Galmés, A. Asumendi, E. Alonso-Tejerina et al., "Terfenadine induces apoptosis and autophagy in melanoma cells through ROS-dependent and -independent mechanisms," Apoptosis, vol. 16, no. 12, pp. 1253-1267, 2011.

[22] M. E. Bulina, D. M. Chudakov, O. V. Britanova et al., "A genetically encoded photosensitizer," Nature Biotechnology, vol. 24, no. 1, pp. 95-99, 2006.

[23] W. Waldeck, E. Heidenreich, G. Mueller, M. Wiessler, K. Tóth, and K. Braun, "ROS-mediated killing efficiency with visible light of bacteria carrying different red fluorochrome proteins," Journal of Photochemistry and Photobiology B: Biology, vol. 109, pp. 28-33, 2012.

[24] M. E. Bulina, K. A. Lukyanov, O. V. Britanova, D. Onichtchouk, S. Lukyanov, and D. M. Chudakov, "Chromophore-assisted light inactivation (CALI) using the phototoxic fluorescent protein KillerRed," Nature Protocols, vol. 1, no. 2, pp. 947-953, 2006.

[25] R. B. Vegh, K. M. Solntsev, M. K. Kuimova et al., "Reactive oxygen species in photochemistry of the red fluorescent protein "Killer Red"," Chemical Communications, vol. 47, no. 17, pp. 4887-4889, 2011.

[26] S. Matsunaga, H. Takata, A. Morimoto et al., "RBMX: a regulator for maintenance and centromeric protection of sister chromatid cohesion," Cell Reports, vol. 1, no. 4, pp. 299-308, 2012.

[27] T. Shibuya and Y. Tsujimoto, "Deleterious effects of mitochondrial ROS generated by KillerRed photodynamic action in human cell lines and C. elegans," Journal of Photochemistry and Photobiology B: Biology, vol. 117, pp. 1-12, 2012.

[28] O. Ivashchenko, P. P. van Veldhoven, C. Brees, Y. S. Ho, S. R. Terlecky, and M. Fransen, "Intraperoxisomal redox balance in mammalian cells: oxidative stress and interorganellar cross-talk," Molecular Biology of the Cell, vol. 22, no. 9, pp. 14401451, 2011.

[29] K. Okatsu, M. Kimura, T. Oka, K. Tanaka, and N. Matsuda, "Unconventional PINK1 localization to the outer membrane of depolarized mitochondria drives Parkin recruitment," Journal of Cell Science, vol. 128, no. 5, pp. 964-978, 2015.

[30] M. Landriscina, F. Maddalena, G. Laudiero, and F. Esposito, "Adaptation to oxidative stress, chemoresistance, and cell survival," Antioxidants \& Redox Signaling, vol. 11, no. 11, pp. 2701-2716, 2009.

[31] H. Chen, G. D. Wang, Y. J. Chuang et al., "Nanoscintillator-mediated X-ray inducible photodynamic therapy for in vivo cancer treatment," Nano Letters, vol. 15, no. 4, pp. 22492256, 2015.

[32] C. Zhang, K. Zhao, W. Bu et al., "Marriage of scintillator and semiconductor for synchronous radiotherapy and deep photodynamic therapy with diminished oxygen dependence," Angewandte Chemie International Edition, vol. 54, no. 6, pp. 1770$1774,2015$.

[33] P. Rajaputra, G. Nkepang, R. Watley, and Y. You, "Synthesis and in vitro biological evaluation of lipophilic cation 
conjugated photosensitizers for targeting mitochondria," Bioorganic \& Medicinal Chemistry, vol. 21, no. 2, pp. 379387, 2013.

[34] P. Rich, "Chemiosmotic coupling: the cost of living," Nature, vol. 421, no. 6923, p. 583, 2003.

[35] S. R. Chowdhury, S. Sengupta, S. Biswas et al., "Low fucose containing bacterial polysaccharide facilitate mitochondriadependent ROS-induced apoptosis of human lung epithelial carcinoma via controlled regulation of MAPKs-mediated Nrf2/Keap1 homeostasis signaling," Molecular Carcinogenesis, vol. 54, no. 12, pp. 1636-1655, 2015.

[36] P. Costantini, E. Jacotot, D. Decaudin, and G. Kroemer, "Mitochondrion as a novel target of anticancer chemotherapy," JNCI: Journal of the National Cancer Institute, vol. 92, no. 13, pp. 1042-1053, 2000.

[37] N. Zamzami, P. Marchetti, M. Castedo et al., "Reduction in mitochondrial potential constitutes an early irreversible step of programmed lymphocyte death in vivo," The Journal of Experimental Medicine, vol. 181, no. 5, pp. 1661-1672, 1995.

[38] N. Zamzami, P. Marchetti, M. Castedo et al., "Sequential reduction of mitochondrial transmembrane potential and generation of reactive oxygen species in early programmed cell death," The Journal of Experimental Medicine, vol. 182, no. 2, pp. 367-377, 1995.

[39] K. S. McCommis and C. P. Baines, "The role of VDAC in cell death: friend or foe," Biochimica et Biophysica Acta (BBA) Biomembranes, vol. 1818, no. 6, pp. 1444-1450, 2012.

[40] V. Shoshan-Barmatz, N. Keinan, and H. Zaid, "Uncovering the role of VDAC in the regulation of cell life and death," Journal of Bioenergetics and Biomembranes, vol. 40, no. 3, pp. 183-191, 2008.

[41] S. Shimizu, Y. Shinohara, and Y. Tsujimoto, "Bax and Bcl-xL independently regulate apoptotic changes of yeast mitochondria that require VDAC but not adenine nucleotide translocator," Oncogene, vol. 19, no. 38, pp. 4309-4318, 2000.

[42] J. S. Lee, T. Q. Huang, T. H. Kim et al., "Radiofrequency radiation does not induce stress response in human $\mathrm{T}$ lymphocytes and rat primary astrocytes," Bioelectromagnetics, vol. 27, no. 7, pp. 578-588, 2006.

[43] M. C. Kahya, M. Nazıroğlu, and B. Çiğ, "Selenium reduces mobile phone (900 MHz)-induced oxidative stress, mitochondrial function, and apoptosis in breast cancer cells," Biological Trace Element Research, vol. 160, no. 2, pp. 285-293, 2014.

[44] Y. Shi, "Apoptosome: the cellular engine for the activation of caspase-9," Structure, vol. 10, no. 3, pp. 285-288, 2002.

[45] D. S. Izyumov, L. V. Domnina, O. K. Nepryakhina et al., "Mitochondria as source of reactive oxygen species under oxidative stress. Study with novel mitochondria-targeted antioxidants - the "Skulachev-ion" derivatives," Biochemistry, vol. 75, no. 2, pp. 123-129, 2010.

[46] G. Petrosillo, G. Casanova, M. Matera, F. M. Ruggiero, and G. Paradies, "Interaction of peroxidized cardiolipin with rat-heart mitochondrial membranes: induction of permeability transition and cytochrome c release," FEBS Letters, vol. 580, no. 27, pp. 6311-6316, 2006. 


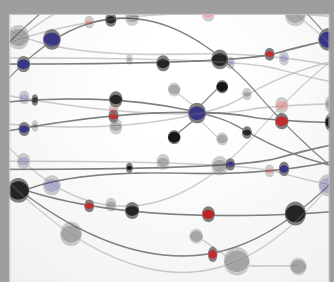

The Scientific World Journal
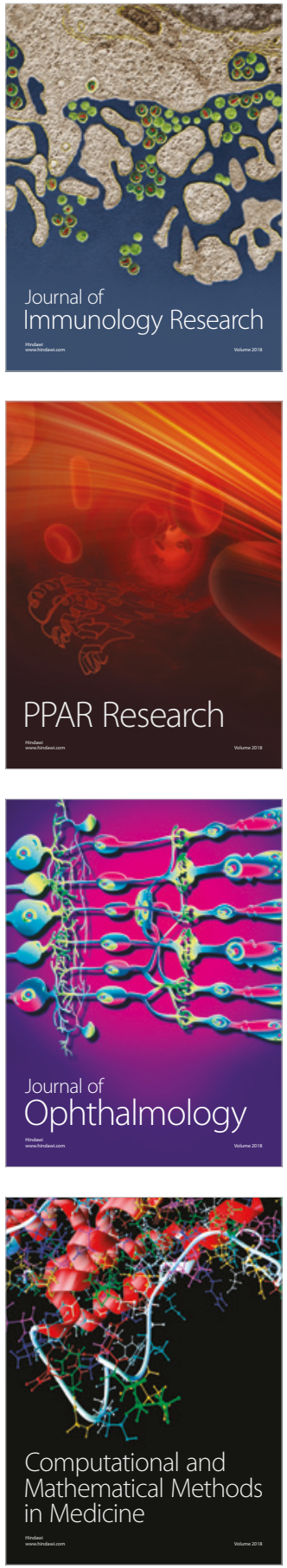

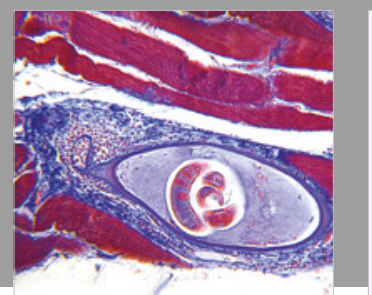

Gastroenterology Research and Practice

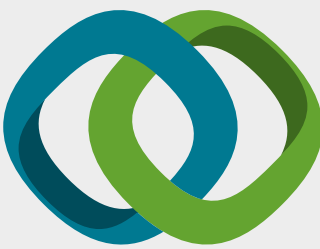

\section{Hindawi}

Submit your manuscripts at

www.hindawi.com
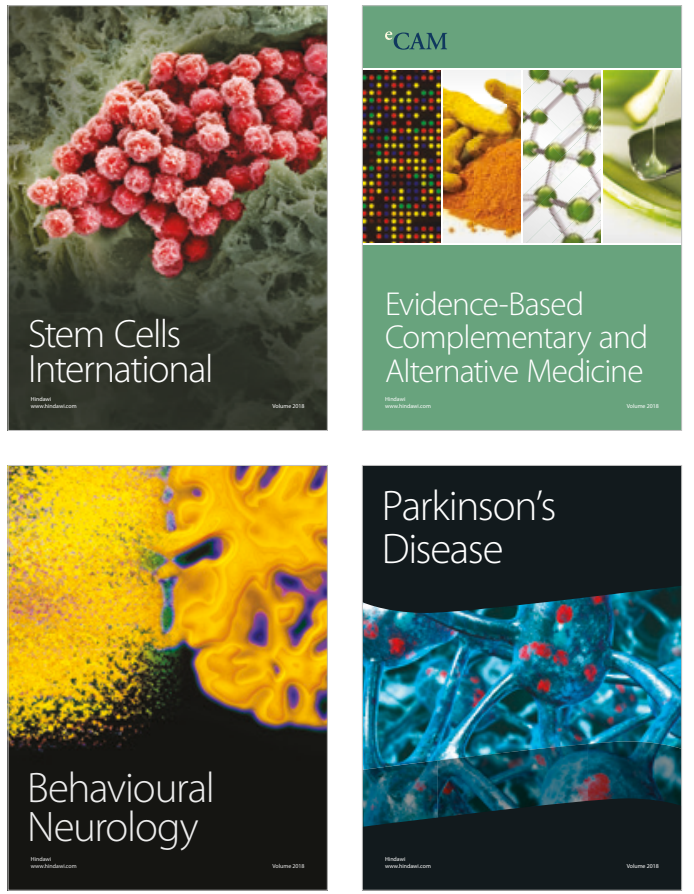

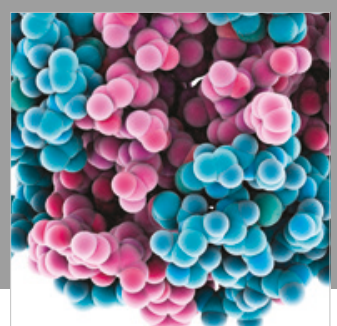

ournal of

Diabetes Research

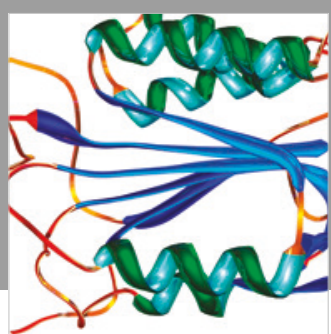

Disease Markers
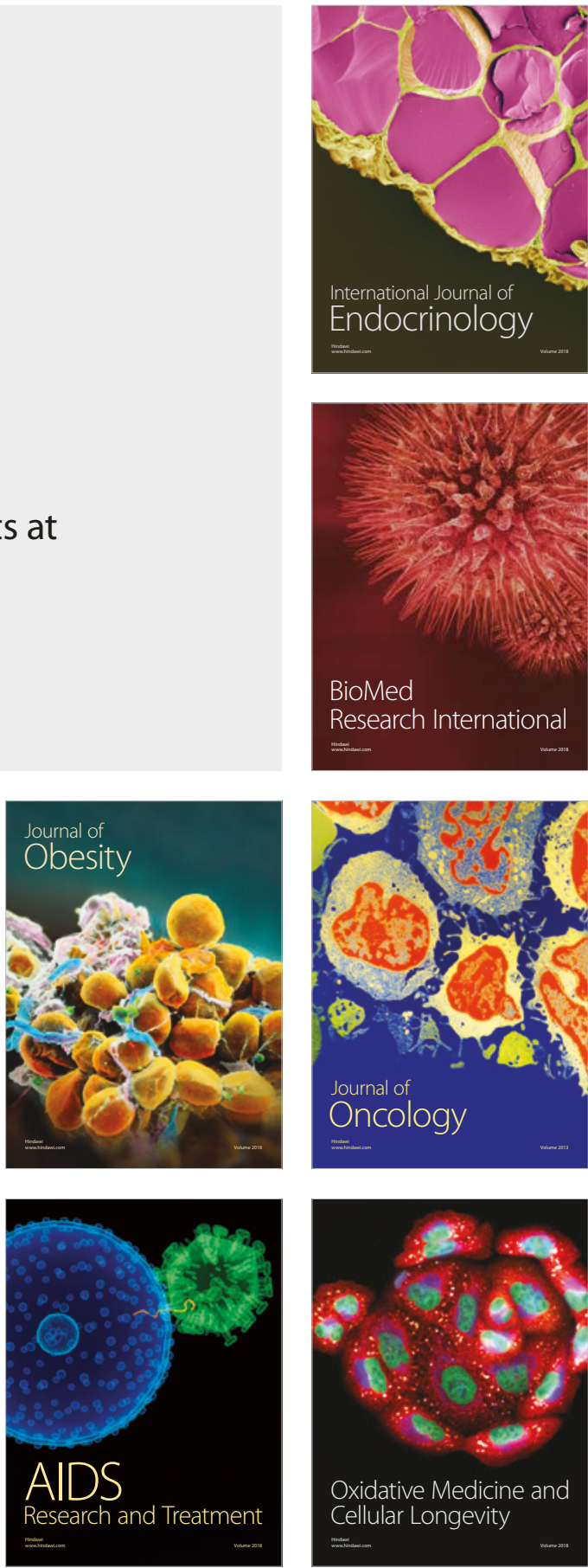